\title{
Development of a questionnaire to assess maternal attitudes towards infant growth and milk feeding practices
}

\author{
Rajalakshmi R Lakshman ${ }^{1,4^{*}}$, Jill R Landsbaugh ${ }^{1,4}$, Annie Schiff ${ }^{1,4}$, Wendy Hardeman², Ken K Ong ${ }^{1,3,4}$ and
} Simon J Griffin ${ }^{1,4}$

\begin{abstract}
Background: There is increasing recognition that public health strategies to prevent childhood obesity need to start early in life. Any behavioural interventions need to target maternal attitudes and infant feeding practices, This paper describes the development and preliminary validation of a questionnaire to assess maternal attitudes towards infant growth and milk feeding practices.

Methods: We designed a 57-item (19 questions), self-administered questionnaire to measure the following four domains- 1) type of milk feeding, decision making and sources of advice; 2) frequency and quantity of milk feeds; 3) attitudes to infant feeding and growth; and 4) theory-based beliefs about following infant feeding recommendations. Forty mothers completed the questionnaire on two occasions six days apart (to assess testretest reliability) and then participated in a semi-structured, open-ended telephone interview covering the same domains (to assess criterion validity). Percentage agreement, Cohen's Kappas (for categorical variables) and Spearman's correlation coefficients (for continuous variables) were used to quantify reliability and validity. Internal consistency between theory-based constructs (self-efficacy, outcome expectancy and intention) was quantified by Chronbach's alpha.
\end{abstract}

Results: Of the 57 questionnaire items 51 (89\%) had percentage agreement above 70\% indicating good test-retest reliability, and the remaining 6 items had moderate or substantial levels of agreement (kappa 0.41-0.68). Comparing questionnaire with interview coding (validity), percentage agreement was above 66\% for 39/57 items (68\%). Of the 16 items with percentage agreement below 66\%, only five had kappa values below 0.20 (two items had insufficient interview responses). Internal consistency was $0.51,0.79$ and 0.90 for self-efficacy, outcome expectancy and intention respectively.

Conclusions: This questionnaire could be a useful tool in understanding the determinants of infant feeding and the 'causal mechanism' of interventions that target infant feeding practices to prevent early obesity.

Keywords: infant feeding nutrition, growth, attitudes, obesity prevention

\section{Background}

Rapid weight gain during infancy is recognised as an important risk factor for later obesity [1-3]. Most parents are poor at recognising overweight and obesity in their children [4-7] and one in five children in England are already overweight when they start school [8]. Hence early prevention of obesity has become a national

\footnotetext{
* Correspondence: r1284@mrc-epid.cam.ac.uk

${ }^{1}$ MRC Epidemiology Unit, Cambridge, UK

Full list of author information is available at the end of the article
}

priority $[9,10]$. Informed by the MRC framework for complex interventions [11], we are developing an intervention to reduce formula-milk intake and prevent excess weight gain during infancy which we plan to test in a randomised controlled trial. Systematic reviews of the literature demonstrated gaps in the evidence-base for interventions in this area $[12,13]$ and particularly in our understanding of how parents make decisions concerning the frequency and quantity of infant milk feeds [14]. Although other questionnaires have been
C Biomed Central 
developed to assess child $[15,16]$ and infant [17] feeding practices, there are no instruments to assess milk feeding practices in younger children, hence we developed a questionnaire to identify correlates of infant milk feeding practices. The questionnaire could also be used to assess the effectiveness and mechanism of action of interventions to optimise growth and nutrition during infancy. The objectives of this paper are to describe the process of developing the questionnaire and its preliminary testing. We also describe maternal attitudes and milk feeding practices in this small sample.

\section{Methods}

\section{Questionnaire development}

The purpose of the questionnaire was to assess maternal infant milk feeding practices, mothers' decision making regarding how much and how often to feed their babies, their attitudes to infant feeding and growth, and beliefs about following infant feeding recommendations. The 57-item (19 questions), self-administered questionnaire was developed after conducting literature reviews [18-21] and a qualitative study using a flexible semistructured interview schedule involving 38 parents $(\mathrm{n}=$ 35 mothers). Three main themes emerged on parents' decision-making regarding volume and frequency of formula-milk feeds; i) baby's appetite (if the baby finished the bottle, or cried between feeds, more was added to the next feed), ii) instructions on formula milk tins/ packets (if the baby did not take what it said on the tin, they were offered a feed again after a short gap) iii) baby's growth (as baby's weight increased, feeds were increased). Parents got information on bottle-feeding from various sources -family, friends, other mothers, 'parent support groups', books, magazines, the internet, formula-milk packets, supermarket shelves, health visitors and midwives. The main barriers to reducing formula-milk feeds were concerns that the baby would cry, be hungry, wake up at night and demand more frequent feeds.

An iterative process was used and numerous revisions were made in response to input from groups of researchers and mothers. Content validity was assessed by extensive pilot testing with mothers $(\mathrm{n}=60)$ participating in a birth cohort study (The Cambridge Baby Growth Study) [22]. Questions covered four domains: 1) type of milk feeding, decision making, and sources of advice, 2) frequency and quantity of feeds, 3) attitudes to infant feeding and growth, and 4) theory-based beliefs about following recommendations to reduce formulamilk feed quantities.

\section{Type of milk feeding, decision making, and sources of advice}

Questions related to the type of milk feeding: breastmilk, expressed breastmilk, formula-milk feeds, and type and brand of formula-milk feeds. Regarding decision making about frequency of milk feeds, the question was phrased 'When deciding how often to feed your baby, do you usually... feed your baby on demand, or follow a routine, or do a combination of both?' Regarding decision making on quantity of milk feeds, our qualitative study showed that mothers either followed the guidelines printed on the formula-milk packaging, or based their decisions on the baby's appetite or growth. Hence our question was phrased 'When deciding how much to feed your baby, do you usually...follow guidance, or depend on baby's appetite, or depend on baby's growth?'

Our systematic review [14] reported that mistakes in preparation of formula-milk feeds with formula-milk powder were common. Parents sometimes heaped or tightly packed the scoops or added powder to the bottle first which resulted in an over-concentrated feed. Furthermore parents reported that they did not receive sufficient advice from healthcare providers. Consequently, we included questions on how feeds were prepared, mothers' sources of advice, and which advice was followed. These questions would also be of particular value to the process evaluation of any trial to change parents' infant feeding behaviour.

\section{Frequency and quantity of feeds}

Amount of milk intake may change often during infancy and therefore to quantify the association between milk intake and infant growth, it may be necessary to assess milk intake frequently (every 4-6 weeks in the first six months). A 4 day diet diary would be burdensome for mothers of newborn infants to complete frequently, hence the following questions were developed as a pragmatic substitute. Example questions include 'In a typical 24 hour period how much formula milk does your baby have? Amount of formula milk per feed? Number of formula feeds per day? Number of scoops of formula milk powder per feed? Duration of typical daytime feed?' Similar questions were included for breastfeeds, water and other drinks. In order to assess whether milk feeds were replaced by solid/semi-solid foods, we included questions relating to these, for example 'What was your baby's age in months when you started solid/semi-solid food?'

\section{Attitudes to infant feeding and growth}

A literature review identified validated questionnaires on breastfeeding self-efficacy [18-21] and self-efficacy in infant care [23,24]. These were used to develop questions to assess mother's confidence (self-efficacy) [25] in infant growth monitoring and feeding so that her baby would not gain too much weight. The questions included eight items, each scored on a five-point Likerttype scale from 'strongly agree' to 'strongly disagree'. For example 'I am confident that I can feed my baby so they do not gain too much weight'. A single question on 
perception of size -'Do you think your baby is... underweight, OR about right, OR overweight?', was derived from a published study [26].

\section{Theory-based beliefs about following recommendations to} reduce formula-feed quantities

In 2004 the World Health Organisation (WHO) and other international bodies reduced their recommendations for energy requirements during infancy from previous (1985) recommendations [27]. Mothers' beliefs about following these new recommendations would influence whether the recommendations were followed. The 11 items in this domain were chosen to measure self-efficacy (confidence in performing a behaviour and overcoming barriers to that behaviour), outcome expectancies (expectation that a positive outcome will occur as a function of that behaviour)-the hypothesised mediators of behaviour change according to Social Cognitive Theory $[28,29]$, and intentions as informed by Theory of Planned Behaviour [30]. These could be scored on a five-point Likert-type scale from 'strongly agree' to 'strongly disagree'. Through our qualitative study of 38 mothers we identified the most common barriers to reducing formula-milk feed quantities (baby would cry, remain hungry, wake up frequently), and used these to create the items in this scale. We also wanted to measure the three dimensions of outcome-expectancies (physical, social and self-evaluative) which predict behaviour [29]. The items were worded positively and negatively and presented in random order. For example 'If I follow the new feeding recommendation, my baby will wake up frequently at night' (negative physical outcome expectancy).

\section{Procedures}

Thirty one mothers were recruited from an ongoing birth cohort study [22]. To include a more diverse range of participants, we also recruited nine exclusively formula-milk feeding mothers from a focus group study conducted to inform intervention development. To assess test-retest reliability, following receipt of a completed postal questionnaire, the same questionnaire was posted and mothers were asked to complete it a second time (median time interval between completion of the two questionnaires was 6 days (range 2-16 days).

To validate the questionnaire, no 'gold-standard' existed, therefore semi-structured interviews were used to assess criterion validity as previously reported for the validation of a questionnaire covering correlates of children's physical activity [31]. We developed an openended, semi-structured interview schedule in which participants could make general comments on the questionnaire, clarify the meaning of the questions, and expand on their answers, giving a richer response (see Additional file 1 for interview schedule). After the first questionnaire was returned, an appointment was made for a face-to-face or telephone interview with the mothers. At the start of the interview, it was confirmed that mothers had completed the second questionnaire and they were asked for general comments on the questionnaire. The median time interval between completion of the first questionnaire and interview was 8 days (range 3-16 days). Interviews were conducted by RL or $\mathrm{JL}$, were tape-recorded and were transcribed by an independent company. The interview data were used as the criterion measure against which to compare the participant's first questionnaire responses. For each participant, two researchers ( $R L$ and JL) used the transcripts to fill in a blank questionnaire. This was done independently and blind to the participant's questionnaire responses. For the two questions (questions 16 and 19 with a total of 19 items) which were scored on a five-point Likert type scale, the transcripts were used to mark a collapsed three-point scale 'agree, neutral, disagree'. Once all of the transcripts were coded, the two researcher-completed questionnaires (for each participant) were compared, and in the event of disagreement, consensus was reached by discussion. This final 'agreed' (by both researchers) questionnaire was used as the 'criterion' for comparison against the participant's first questionnaire responses to assess criterion validity.

Approvals for the study were obtained from the local Research Ethics Committee and research governance committees of the local hospital and Primary Care Trust. Demographic details and written informed consent were obtained from all participants.

\section{Statistical Analysis}

All analyses were performed using Stata version 10.1 (Stata Corp LP, College Station, Texas). The test-retest reliability (between $1^{\text {st }}$ and $2^{\text {nd }}$ questionnaires) and criterion validity (between $1^{\text {st }}$ questionnaire and interview coded response) were assessed for each item by calculating percentage exact agreement and chance-corrected agreement (Cohen's kappa). A percentage agreement $\leq$ $66 \%$ was used to indicate fair agreement $[32,33]$ and kappa values were categorized as: poor $(<0.0)$, slight (0.00-0.20), fair (0.21-0.40), moderate (0.41-0.60), substantial (0.61-0.80), and almost perfect (0.81-1.0) agreements [34]. Weighted kappas were calculated for ordinal categorical variables and Spearman's correlation coefficients for continuous variables.

To assess internal consistency we calculated Cronbach's alpha for items measuring theory-based constructs- self-efficacy, outcome-expectancies and intentions. Negatively worded items were re-coded. A summary score for each construct was calculated by summing the individual item scores and dividing by the number of items in the construct (4 for self-efficacy, 5 
for outcome-expectancies and 2 for intentions). The correlations between a summary score for these constructs were calculated.

\section{Results}

Forty mothers completed the first questionnaire; of these two did not complete the $2^{\text {nd }}$ questionnaire and two others did not complete the interview. The mean age of mothers was 34 years (range 21-42 years) and the average age of their babies was 5.2 months (range 3.38.7 months, $55 \%$ girls). Eighty percent of the mothers had one child, $7.5 \%$ had two children and $10 \%$ had three children (1 participant -missing data). The majority were White (95\%), 58\% were professionals and 70\% had degree level or higher qualifications. Ten percent of mothers were exclusively breastfeeding, 55\% feeding exclusively formula-milk and 35\% combined breastfeeds and formula-milk feeds.

\section{Overall results}

The inter-rater agreement between the two researchers coding the interviews was high for 56/57 items (agreement above $80 \%$, kappa above 0.6 ; data not shown). Overall, for test-retest reliability, percentage agreement was good (above 66\%) for 89\% (51/57) of the items. For the remaining 6 items (percentage agreement between $47 \%$ and $66 \%$ ), Cohen's kappa's were moderate or substantial (0.41-0.68). Overall, for validity, percentage agreement was above $66 \%$ for $68 \%(39 / 57)$ of the items. Two items had insufficient data to estimate percentage agreement and of the remaining 16 items, only five had kappa values less than fair $(<0.20)$.

\section{Type of milk feeding, decision making, and sources of advice (Table 1)}

All 21 items in this domain had percentage agreement over $73 \%$ for test-retest reliability and $71 \%$ of the items had percentage agreement over $66 \%$ for validity. Of the six items that had less than 66\% agreement for validity, four related to what advice was followed and two related to how feeds were prepared.

Regarding decisions on the frequency of feeds, $50 \%$ used a combination of demand and routine feeding. When deciding on the quantity of feeds, $93 \%$ were led by the baby's appetite. Sixty-three percent of all mothers (25/40) prepared formula-milk from powder or concentrate and of these $88 \%(22 / 25)$ reported following the advice on the packaging about feed preparation. However, $44 \%(11 / 25)$ of mothers who prepared formula-milk from powder reported that they tightly packed the scoops.

\section{Frequency and quantity of feeds (Table 2)}

Although percentage agreement between the two questionnaires was below $70 \%$ for six items (test-retest reliability), all 16 items in this domain had moderate to almost perfect agreement based on kappa values (above $0.41)$, and $80 \%(13 / 16)$ had kappa values above 0.41 for validity. The three items that had fair validity (Kappa $0.2-0.4)$ were continuous variables: number of breastfeeds, number of formula-milk feeds, duration of breastfeeds, and had correlation coefficients of 0.9, 0.6 and 0.9 respectively. It is unclear whether the questions are not valid or whether feeding practices changed over the duration between the first questionnaire and interview.

The median daily number of breastfeeds was six and the median duration of each feed was ten minutes. The median number of formula-milk feeds was four and median duration was 15 minutes. Eighty percent of mothers had introduced solid foods and 10\% were giving drinks other than water and milk.

\section{General attitudes to infant feeding and growth (Table 3)}

All items had percentage agreement over $70 \%$ for both reliability and validity. There was however not much variation in the responses hence kappa values were low for some of the items.

Seventy percent of the mothers agreed or strongly agreed with the statement that it is possible to feed a baby too little'; whereas only $50 \%$ agreed or strongly agreed with 'it is possible to feed a baby too much' ( $\mathrm{p}=$ 0.002 ). Ninety percent were confident that they could feed their baby so that they gain enough weight; whereas $72 \%$ were confident that they could feed their baby so they do not gain too much weight $(\mathrm{p}<0.001)$. Ninetyeight percent perceived that their baby's weight was about right.

\section{Theory-based beliefs about following recommendations to reduce formula-feed quantities (Table 4)}

The 11 items in this domain measured three constructs - Outcome-expectancies (5 items), Self-efficacy (4 items) and intentions ( 2 items). All items had percentage agreement over $76 \%$ for reliability and $82 \%$ (9/11) items had percentage agreement over $66 \%$ for validity. The two items that had percentage agreement below $66 \%$ (56\% and 64\%) had kappa values of 0.09 and 0.22 .

As quantified by responses to the first questionnaire, mean self-efficacy score was 2.7 (median 3, inter quartile range 2.6-3.3); for outcome-expectancies mean score was 2.7 (median 3, inter quartile range 2.6-3.4); and for intentions mean score was 2.6 (median 3, inter quartile range 2-3.5), on a scale of 1-5. Internal consistency measured by Cronbach's alphas was $0.51,0.79$ and 0.90 for self-efficacy (4 items), outcome-expectancies (5 items) and intentions (2 items) respectively. Correlations between summary scores for self-efficacy, outcomeexpectancy, and intentions were 0.84-0.92 (all p < 0.0001-Table 5), 
Table 1 Type of milk feeding, decisions and advice (21 items)

\begin{tabular}{|c|c|c|c|c|c|c|}
\hline \multicolumn{2}{|l|}{ Question wording } & \multicolumn{2}{|c|}{ Test-retest reliability $^{\mathrm{a}}$} & \multicolumn{2}{|c|}{ Validity $^{\mathbf{b}}$} & \multirow{2}{*}{$\frac{\text { Frequency }^{c}}{\mathrm{n}(\%)}$} \\
\hline What feeding methods are you currently using? $(n=40)$ & Question $^{d}$ & \%Agreement ${ }^{\mathrm{e}}$ & Kappa $^{f}$ & $\%$ Agreement ${ }^{\mathrm{e}}$ & Kappa $^{f}$ & \\
\hline Breast milk directly from the breast & $1 \mathrm{a}$ & 100.0 & 1.00 & 100.0 & 1.00 & $18(45)$ \\
\hline Expressed breast milk from bottle & $1 b$ & 97.3 & 0.91 & 91.9 & 0.68 & $7(18)$ \\
\hline Formula milk, made up from powder or concentrate & $1 c$ & 100.0 & 1.00 & 100.0 & 1.00 & 25(63) \\
\hline Ready-to use formula milk & $1 d$ & 91.9 & 0.79 & 75.7 & 0.24 & $12(30)$ \\
\hline Others & 1e & 86.5 & 0.47 & 86.5 & 0.25 & 7(18) \\
\hline \multicolumn{7}{|c|}{ When deciding how often to feed your baby, do you usually? $(n=40)$} \\
\hline A)Feed your baby on demand & $2 \mathrm{a}$ & 88.9 & 0.75 & 75.7 & 0.49 & $14(35)$ \\
\hline B) Follow a routine & $2 b$ & 91.4 & 0.72 & 83.8 & 0.42 & $9(23)$ \\
\hline Do a combination of $A$ and $B$ & 2c & 82.9 & 0.66 & 70.3 & 0.40 & $21(50)$ \\
\hline \multicolumn{7}{|c|}{ When deciding how much to feed your baby, do you usually? $(n=40)$} \\
\hline Follow guidance & 17 & 92.1 & 0.36 & 91.9 & -0.04 & $3(7)$ \\
\hline Depend on baby's appetite & & & & & & $37(93)$ \\
\hline Depend on baby's growth & & & & & & $0(0)$ \\
\hline \multicolumn{7}{|c|}{ Which brand, and type of formula milk do you usually use? $(n=26)$} \\
\hline Brand & $6 a$ & 87.5 & 0.83 & 87.5 & 0.83 & \\
\hline Type & $6 b$ & 82.6 & 0.71 & 79.0 & 0.65 & \\
\hline \multicolumn{7}{|c|}{ If you make up formula from milk powder, are the scoops usually? $(n=25)$} \\
\hline rounded/heaped OR flat & $11 a$ & 92.7 & 0.85 & \multicolumn{2}{|c|}{ Insufficient responses } & $0(0)$ \\
\hline loosely packed OR tightly packed & $11 b$ & 78.3 & 0.56 & 54.6 & 0.07 & $14(56)$ \\
\hline do you add powder first OR water first & $11 \mathrm{c}$ & 100.0 & 1.00 & 100.0 & 1.00 & $1(4)$ \\
\hline \multicolumn{7}{|c|}{$\begin{array}{l}\text { If you received/read advice on formula } \\
\text { feed preparation, we would like to know which advice you followed. }(n=25)\end{array}$} \\
\hline Midwife & $12 a$ & 78.3 & 0.57 & 66.7 & 0.23 & $9(36)$ \\
\hline Health visitor & $12 b$ & 73.9 & 0.59 & 45.8 & 0.07 & $12(48)$ \\
\hline Friends & $12 c$ & 87.0 & 0.76 & 50.0 & 0.11 & $13(52)$ \\
\hline Family & $12 d$ & 78.3 & 0.59 & 41.7 & 0.02 & $13(52)$ \\
\hline Formula milk packet or tin & $12 e$ & 73.9 & 0.55 & 62.5 & 0.32 & $22(88)$ \\
\hline Leaflet & $12 f$ & 90.9 & 0.81 & 75.0 & 0.10 & $6(24)$ \\
\hline Other & $12 \mathrm{~g}$ & 100.0 & 1.00 & 95.0 & 0.77 & $2(10)$ \\
\hline
\end{tabular}

${ }^{\text {a }}$ Test-retest reliability- $1^{\text {st }}$ and $2^{\text {nd }}$ questionnaires

${ }^{\text {b}}$ Validity- ${ }^{\text {st }}$ questionnaire and interview

${ }^{\mathrm{c}}$ Frequency of respondents $1^{\text {st }}$ questionnaire - for Question 11a- answering scoops rounded/heaped; $11 \mathrm{~b}$ loosely packed; 11c added powder first. For Question $12 \mathrm{a}-12 \mathrm{~g}$ answering followed all or some of the advice.

${ }^{\mathrm{d}}$ Question- Question number

${ }^{\mathrm{e}}$ Agreement- Percentage exact agreement- over $66 \%$ good agreement

${ }^{f}$ Kappa- Chance corrected agreement or Cohen's Kappa- < 0 poor; 0-0.20 slight; 0.21-0.40 fair; 0.41-0.60 moderate; 0.61-0.8 substantial; 0.81-1 almost perfect

\section{Discussion}

We have developed a questionnaire to assess infant milk feeding practices and maternal attitudes. Test-retest reliability was good with $89 \%$ of the items having percentage agreement above $70 \%$ and the remaining six items having kappa values between 0.41-0.68 (moderate or substantial agreement). Comparing questionnaire with interview coding (criterion validity), percentage agreement was below $66 \%$ for $28 \%(16 / 57)$ of the items and of these five had kappa values below 0.20 . We believe that this may have been due to the open-ended nature of the interview rather than the questionnaire which meant that it was not possible to code many of the interview responses. For example, in the interviews we asked 'How do you usually make up formula feeds', and 'have you received any advice on formula-feed preparation?' Often it was not possible to code the questionnaires (in which very specific questions were asked) based on the interview responses.

The low internal consistency for four items measuring self-efficacy (Cronbach's alpha 0.5 ) was probably because although many mothers $(23 / 35)$ were confident about following the infant feeding recommendations even if their friends did not follow them, fewer were confident about following the infant feeding recommendations if their partner or family did not support them (10/35), or if their baby cried between feeds (6/35) suggesting that the barriers may be quite distinct. 
Table 2 Frequency and quantity of feeds (16 items)

\begin{tabular}{|c|c|c|c|c|c|c|c|c|c|}
\hline \multirow[t]{2}{*}{ Question wording } & \multirow[b]{2}{*}{ Question $^{c}$} & \multicolumn{3}{|c|}{$\frac{\text { Test-retest }^{\text {reliability }}}{\text { rela }^{a}}$} & \multicolumn{2}{|c|}{ Validity $^{\text {b }}$} & \multirow[b]{2}{*}{$\operatorname{Kap}^{f}$} & \multirow[b]{2}{*}{ Median } & \multirow[b]{2}{*}{ Range } \\
\hline & & Corr $^{\mathrm{d}}$ & $\% \mathrm{Ag}^{\mathrm{e}}$ & $\mathrm{Kap}^{f}$ & Corr $^{d}$ & $\% \mathrm{Ag}^{\mathrm{e}}$ & & & \\
\hline \multicolumn{10}{|l|}{ Breastfeeding } \\
\hline \multicolumn{10}{|l|}{$\begin{array}{l}\text { In a typical } 24 \text { hour period, how many breastfeeds } \\
\text { does your baby have? }\end{array}$} \\
\hline Number of feeds directly from the breast $(n=20)$ & 3a & 0.92 & 47.4 & 0.41 & 0.86 & 26.7 & 0.20 & 6 & $0-12$ \\
\hline Number of feeds of expressed breast milk $(n=17)$ & $3 b$ & 0.84 & 91.7 & 0.85 & 0.58 & 75.0 & 0.57 & 0 & $0-8$ \\
\hline Amount of expressed breast milk per feed $(n=12)$ & 5 & 0.87 & 70.0 & 0.61 & 0.88 & 62.5 & 0.55 & $30 \mathrm{ml}$ & $0-250 \mathrm{ml}$ \\
\hline How many minutes does a typical daytime breastfeed & 4 & 0.91 & 50.0 & 0.44 & 0.88 & 43.8 & 0.37 & 10 mins & $0-30$ mins \\
\hline
\end{tabular}

directly from the breast last? $(n=19)$

\section{Formula-feeding}

In a typical 24 hour period, how much formula milk does your baby have?

Amount of formula milk per feed $(n=26)$

Number of formula feeds per day $(n=25)$

How many minutes does a typical daytime bottle feed last? $(\mathrm{n}=25)$

Most of the time, how much milk is left in the bottle when your baby has finished feeding?

none, a little, or a lot $(n=25)$

What was your baby's age in weeks when you first started formula feeds? $(n=26)$

How many scoops of formula milk powder do you usually use per feed? $(n=25)$

$\begin{array}{llllllllr}7 a & 0.74 & 52.2 & 0.43 & 0.79 & 58.3 & 0.47 & 210 \mathrm{ml} & 60-960 \mathrm{mls} \\ 7 \mathrm{~b} & 0.57 & 73.9 & 0.68 & 0.58 & 45.5 & 0.37 & 4 & 1-8 \\ 8 & 0.81 & 63.6 & 0.54 & 0.94 & 52.2 & 0.44 & 15 \mathrm{mins} & 5-30 \mathrm{mins}\end{array}$

\section{Other drinks}

If your baby has water, how much water does your baby have?

Amount of water per drink $(n=30)$

Number of drinks of water per day $(n=28)$

Does your baby have any drink other than milk or water? Yes OR No $(n=40)$

\section{Solids/Semi-solids}

Does your baby have any solid/semi-solid food? Yes OR No $(n=40)$

What was your baby's age in months when you started solid/semi-solid food? $(n=32)$

How many times per day does your baby have solid/ semi-solid food? $(n=32)$

$\begin{array}{ccccccccc}9 & 0.84 & 91.3 & 0.78 & 0.63 & 83.3 & 0.57 & 72 \%-\text { a little } \\ 10 & 0.82 & 62.5 & 0.51 & 0.94 & 64.0 & 0.55 & 1.5 \text { wks } & 0-15 \text { wks } \\ 11 d & 0.73 & 73.9 & 0.62 & 0.64 & 70.6 & 0.52 & 7 \text { scoops } & 2-8 \text { scoops }\end{array}$

${ }^{\text {a }}$ Test-retest reliability- $1^{\text {st }}$ and $2^{\text {nd }}$ questionnaires

${ }^{\mathrm{b}}$ Validity- $1^{\text {st }}$ questionnaire and interview

${ }^{c}$ Question- Question number

${ }^{\mathrm{d} C o r r}$-Spearman's correlation coefficient

$\mathrm{e}_{\%} \mathrm{Ag}$ - Percentage exact agreement- over $66 \%$ good agreement

${ }^{f}$ Kap- Chance corrected agreement or Cohen's Kappa- < 0 poor; 0-0.20 slight; 0.21-0.40 fair; 0.41-0.60 moderate; 0.61-0.8 substantial; 0.81-1 almost perfect

During the interview, mothers suggested that two of the items that asked about the possibility of feeding 'a' baby too much or too little could be reworded to specify 'my' baby (Question 16). They also said that the stem of question 19 which read 'New research suggests that babies should be given less formula milk than what is currently recommended on the formula milk packets/ tins...'was difficult to answer without knowing how much lower the new recommendations were. We have changed this in the current version of the questionnaire to read 'We would like to know your views on following the feeding recommendations available to you, on how much milk your baby needs...'. Since these two questions have been changed (question16 and 19), future studies will have to confirm their validity in a larger sample to explore the underlying factor structure.

While all of the mothers thought that it was important to monitor the growth of their babies, only half of them thought that it was possible to feed a baby too much. Among the mothers who prepared formula-milk feeds 
Table 3 Maternal attitudes to infant growth and feeding (9 items, $n=40$ )

\begin{tabular}{|c|c|c|c|c|c|c|c|c|c|c|}
\hline \multirow[t]{2}{*}{ Question Wording } & \multirow[b]{2}{*}{ Question } & \multicolumn{2}{|c|}{$\frac{\text { Test- Retest }^{\text {reliability }}}{\text { a }^{\mathrm{a}}}$} & \multicolumn{2}{|c|}{$\frac{\text { Collapsed } 3}{\text { categories }^{\circ}}$} & \multicolumn{2}{|c|}{ Validity $^{c}$} & \multicolumn{2}{|c|}{ Frequency $^{\text {d }}$} & \multirow[b]{2}{*}{-ve } \\
\hline & & $\begin{array}{c}\% \\
\text { agreement }\end{array}$ & Kappa & $\begin{array}{c}\% \\
\text { agreement }\end{array}$ & Kappa & $\begin{array}{l}\% \\
\text { agreement }\end{array}$ & Kappa & +ve & neutral & \\
\hline \multicolumn{11}{|l|}{ Attitudes to growth } \\
\hline $\begin{array}{l}\text { I think it is important to monitor the growth of } \\
\text { my baby }\end{array}$ & $16 a$ & 89.5 & 0.78 & \multicolumn{4}{|c|}{ Insufficient variability in response } & 40 & 0 & 0 \\
\hline $\begin{array}{l}\text { I would be worried if my baby was gaining too } \\
\text { little weight }\end{array}$ & $16 b$ & 94.7 & 0.84 & 100.0 & 1.00 & 93.2 & 0.48 & 34 & 6 & 0 \\
\hline $\begin{array}{l}\text { I would be worried if my baby was gaining too } \\
\text { much weight }\end{array}$ & $16 c$ & 85.1 & 0.42 & 85.5 & 0.38 & 85.1 & 0.52 & 33 & 3 & 4 \\
\hline \multicolumn{11}{|l|}{ Attitudes to feeding } \\
\hline It is possible to feed a baby too much & $16 \mathrm{e}$ & 90.8 & 0.69 & 89.5 & 0.78 & 73.6 & 0.47 & 20 & 4 & 16 \\
\hline It is possible to feed a baby too little & $16 f$ & 92.1 & 0.73 & 89.5 & 0.74 & 70.8 & 0.44 & 28 & 3 & 9 \\
\hline \multicolumn{11}{|l|}{ Self-efficacy to monitor growth } \\
\hline $\begin{array}{l}\text { I am confident that I can get my baby } \\
\text { measured if I was concerned about their } \\
\text { growth }\end{array}$ & $16 d$ & 82.9 & 0.36 & 97.4 & 0.00 & 97.3 & 0.00 & 39 & 1 & 0 \\
\hline \multicolumn{11}{|l|}{ Self-efficacy for appropriate feeding } \\
\hline $\begin{array}{l}\text { I am confident that I can feed my baby so they } \\
\text { do not gain too much weight }\end{array}$ & $16 \mathrm{~g}$ & 91.5 & 0.57 & 89.5 & 0.60 & 82.4 & 0.00 & 29 & 8 & 3 \\
\hline $\begin{array}{l}\text { I am confident that I can feed my baby so they } \\
\text { gain enough weight }\end{array}$ & $16 \mathrm{~h}$ & 92.8 & 0.42 & 93.4 & 0.50 & 91.9 & 0.00 & 36 & 2 & 2 \\
\hline \multicolumn{2}{|l|}{ Perception of baby's weight } & & & & & & & under & right & over \\
\hline $\begin{array}{l}\text { Do you think your baby is underweight OR } \\
\text { about right OR overweight }\end{array}$ & 18 & 100.0 & 1.00 & $\mathrm{n} / \mathrm{a}$ & $n / a$ & 100.0 & 1.00 & 1 & 39 & 0 \\
\hline
\end{tabular}

${ }^{\text {a }}$ Test-retest reliability- $1^{\text {st }}$ and $2^{\text {nd }}$ questionnaires

${ }^{\mathrm{b}} 1^{\text {st }}$ and $2^{\text {nd }}$ Questionnaires coded as positive, or neutral, or negative

${ }^{\mathrm{C}}$ Validity- $1^{\text {st }}$ questionnaire and interview coded as positive, or neutral, or negative

${ }^{\mathrm{d}}$ Frequency of respondents $1^{\text {st }}$ questionnaire

from powder, forty percent tightly packed the scoops. These attitudes could contribute to higher growth rate and obesity levels among formula-milk fed babies by overconcentration of milk feeds.

\section{Strengths and limitations}

The main strengths of this study are that the participants were mothers of infants using a variety of feeding methods (exclusive breastfeeding, exclusive formula-milk feeds and a combination). The validity and reliability are comparable to other questionnaires measuring attitudes and behaviours $[19,35]$. The questions on frequency and quantity of milk feeds can be administered frequently during the first six months of life (in large-scale intervention and observational studies) to measure energy intake and to study the association between energy intake and infant growth. The questions on attitudes and theory-based beliefs can be used to study differences between populations and to assess intervention mediation pathways in obesity prevention trials starting in early life.

The time interval between two questionnaires was approximately one week and reliability may be lower if the time interval is longer. However since feeding practices change very frequently during infancy, we did not think that it would be appropriate to have a longer time interval because we could be measuring actual change in feeding practices.

Although our preliminary validation suggests that the tool could be useful, gold-standard psychometric methods to comprehensively evaluate the tool in a larger sample and different populations will be necessary to confirm acceptability, reliability and validity [36]. Another limitation of the small sample size was that it was not possible to explore important issues such as the influence of feeding behaviours, timing of completion of questionnaires and participant demographics. Many mothers participating in the study were 'White', had 'degree' level qualifications and a 'professional' occupation which may have influenced our findings. Ten percent of mothers were exclusively breastfeeding and data from the UK National Infant Feeding Survey suggest that $1 \%$ of mothers exclusively breastfed at six months [37].

\section{Conclusions}

We have developed a questionnaire to measure milkfeeding practices and maternal attitudes to feeding and growth in early life. This questionnaire could be a useful 
Table 4 Theory-based beliefs about following recommendations to reduce formula-milk feed quantities $(11$ items, $\mathbf{n}=$ 35)

\begin{tabular}{|c|c|c|c|c|c|c|c|c|c|c|}
\hline \multirow[t]{2}{*}{ Question Wording } & \multirow[b]{2}{*}{ Question } & \multicolumn{2}{|c|}{$\frac{\text { Test- retest }^{\text {reliability }}}{\text { a }^{\mathrm{a}}}$} & \multicolumn{2}{|c|}{$\frac{\text { Collapsed } 3}{\text { categories }^{\circ}}$} & \multicolumn{2}{|c|}{ Validity $^{\mathrm{c}}$} & \multicolumn{3}{|c|}{ Frequency $^{\text {d }}$} \\
\hline & & $\begin{array}{c}\% \\
\text { agreement }\end{array}$ & Kappa & $\begin{array}{c}\% \\
\text { agreement }\end{array}$ & Kappa & $\begin{array}{c}\% \\
\text { agreement }\end{array}$ & Kappa & + ve & neutral & -ve \\
\hline \multicolumn{11}{|l|}{ Positive outcome expectancy } \\
\hline $\begin{array}{l}\text { If I follow the new feeding recommendation, my } \\
\text { baby's } \\
\text { growth will be optimal }\end{array}$ & $19 a$ & 76.7 & 0.24 & 79.7 & 0.24 & 75.0 & 0.19 & 6 & 25 & 3 \\
\hline $\begin{array}{l}\text { If I follow the new feeding recommendation, I will } \\
\text { feel good } \\
\text { about myself }\end{array}$ & $19 b$ & 87.9 & 0.44 & 83.3 & 0.54 & 66.0 & 0.21 & 9 & 17 & 9 \\
\hline $\begin{array}{l}\text { If I follow the new feeding recommendation, I will } \\
\text { feel } \\
\text { I do the best for my baby }\end{array}$ & $19 c$ & 89.9 & 0.62 & 86.4 & 0.66 & 76.0 & 0.37 & 14 & 15 & 6 \\
\hline \multicolumn{11}{|l|}{ Negative outcome expectancy (reverse coded) } \\
\hline $\begin{array}{l}\text { If I follow the new feeding recommendation, my } \\
\text { baby } \\
\text { will remain hungry }\end{array}$ & $19 \mathrm{~g}$ & 89.1 & 0.40 & 79.7 & 0.33 & 70.8 & 0.32 & 8 & 22 & 3 \\
\hline $\begin{array}{l}\text { If I follow the new feeding recommendation, my } \\
\text { baby } \\
\text { will wake up frequently at night }\end{array}$ & $19 \mathrm{~h}$ & 91.4 & 0.47 & 84.4 & 0.44 & 68.0 & 0.31 & 6 & 24 & 4 \\
\hline \multicolumn{11}{|l|}{ Positive self-efficacy } \\
\hline $\begin{array}{l}\text { I am confident that I can follow the new feeding } \\
\text { recommendation even if my baby cries between } \\
\text { feeds }\end{array}$ & $19 d$ & 91.9 & 0.76 & 90.9 & 0.77 & 76.0 & 0.37 & 6 & 12 & 17 \\
\hline $\begin{array}{l}\text { I am confident that I can follow the new feeding } \\
\text { recommendation } \\
\text { even if my friends do not follow the same } \\
\text { recommendation }\end{array}$ & $19 e$ & 85.6 & 0.23 & 77.3 & 0.23 & 80.0 & 0.00 & 23 & 11 & 1 \\
\hline \multicolumn{11}{|l|}{ Negative self-efficacy (reverse coded) } \\
\hline $\begin{array}{l}\text { It would be difficult for me to follow the new } \\
\text { feeding } \\
\text { recommendation if my partner and family do not } \\
\text { support me }\end{array}$ & $19 f$ & 86.4 & 0.69 & 86.4 & 0.69 & 56.0 & 0.09 & 10 & 12 & 13 \\
\hline $\begin{array}{l}\text { It would be difficult for me to follow the new } \\
\text { feeding } \\
\text { recommendation }\end{array}$ & $19 k$ & 89.1 & 0.45 & 82.8 & 0.51 & 68.0 & 0.27 & 10 & 17 & 7 \\
\hline \multicolumn{11}{|l|}{ Intentions } \\
\hline $\begin{array}{l}\text { I intend to follow the new feeding } \\
\text { recommendation }\end{array}$ & $19 i$ & 90.6 & 0.65 & 87.5 & 0.65 & 64.0 & 0.22 & 8 & 19 & 7 \\
\hline $\begin{array}{l}\text { I will try to follow the new feeding } \\
\text { recommendation }\end{array}$ & $19 j$ & 92.7 & 0.75 & 92.2 & 0.81 & 70.0 & 0.32 & 14 & 12 & 8 \\
\hline
\end{tabular}

${ }^{\mathrm{a}}$ Test-retest reliability- $1^{\text {st }}$ and $2^{\text {nd }}$ questionnaires

${ }^{b} 1^{\text {st }}$ and $2^{\text {nd }}$ Questionnaires coded as positive, or neutral, or negative with negatively worded items reverse coded

${ }^{c}$ Validity- $1^{\text {st }}$ questionnaire and interview coded as positive, or neutral, or negative with negatively worded items reverse coded

${ }^{d}$ Frequency of respondents $1^{\text {st }}$ questionnaire with negatively worded items reverse coded

Table 5 Correlation coefficients between summary score for self-efficacy, outcome-expectancies and intentions ( $n=35)$

\begin{tabular}{lll}
\hline & Outcome-expectancies & Intentions \\
\hline Self-efficacy & 0.92 & 0.84 \\
Outcome-expectancies & & 0.85 \\
\hline
\end{tabular}

tool to provide much needed insight in the 'causal mechanism' of interventions that target infant feeding practices to prevent early obesity.

\section{Funding}

The study was supported by the Medical Research Council and the Centre for Diet and Activity Research (CEDAR), a UKCRC Public Health Research Centre of Excellence, which is funded by the British Heart Foundation, Department of Health, Economic and Social 
Research Council, Medical Research Council, and the Wellcome Trust, under the auspices of the UKCRC. RL is supported by a MRC Health Services and Health of the Public Research Fellowship and is in receipt of a Raymond and Beverley Sackler fellowship.

\section{Ethical Approval}

Cambridgeshire 1 Research Ethics committee 09/H0304/

25 and Essex 2 Research Ethics committee 08/H0302/47.

\section{Additional material}

\section{Additional file 1: Interview schedule}

\section{Acknowledgements}

We would like to thank all the participants for their generous help. Thanks also to Dr Alison McMinn who advised us on the statistical analysis and on the interview assessments of criterion validity.

\section{Author details}

${ }^{1}$ MRC Epidemiology Unit, Cambridge, UK. ${ }^{2}$ Department of Public Health and Primary Care, University of Cambridge, UK. ${ }^{3}$ Department of Paediatrics, University of Cambridge, UK. ${ }^{4}$ UKCRC Centre for Diet and Activity Research, Cambridge, UK.

\section{Authors' contributions}

$\mathrm{RL}$ developed the questionnaire with input from all co-authors. $R L$ and $J$ conducted the interviews. RL analysed the data and wrote the first draft. All authors contributed to the study design, critical revision of the manuscript, and approved the final version.

\section{Competing interests}

The authors declare that they have no competing interests.

Received: 20 October 2010 Accepted: 21 April 2011

Published: 21 April 2011

\section{References}

1. Baird J, Fisher D, Lucas P, Kleijnen J, Roberts H, Law C: Being big or growing fast: systematic review of size and growth in infancy and later obesity. BMJ 2005, 331:929.

2. Monteiro PO, Victora CG: Rapid growth in infancy and childhood and obesity in later life a systematic review. Obes Rev 2005, 6:143-154.

3. Ong KK, Loos RJ: Rapid infancy weight gain and subsequent obesity: systematic reviews and hopeful suggestions. Acta Paediatr 2006, 95:904-908.

4. Towns N, D'Auria J: Parental Perceptions of Their Child's Overweight: An Integrative Review of the Literature. Journal of Pediatric Nursing 2009, 24:115-130.

5. Eckstein KC, Mikhail LM, Ariza AJ, Thomson JS, Millard SC, Binns HJ: Parents' Perceptions of Their Child's Weight and Health. Pediatrics 2006, 117:681-690.

6. Manios Y, Kondaki K, Kourlaba G, Vasilopoulou E, Grammatikaki E: Maternal perceptions of their child's weight status: the GENESIS study. Public Health Nutrition 2009, 12:1099-1105.

7. Miller JC, Grant AM, Drummond BF, Williams SM, Taylor RW, Goulding A: DXA measurements confirm that parental perceptions of elevated adiposity in young children are poor. Obesity 2007, 15:165-171.

8. Dinsdale $\mathrm{H}$, Rutter $\mathrm{H}$ : National Child Measurement Programme: Detailed Analysis of the 2006/07 National Dataset.[http://www.noo.org.uk/uploads/ doc168_2_NOO_NCMP_report230608.pdf], accessed 5th April 2011.

9. Butland B, Jebb S, Kopelman P, McPherson K, Thomas S, Mardell J: Tackling Obesities: Future Choices (Foresight Project Report). Government Office for Science, London; 2008.
10. Department of Health: Healthy Weight, Healthy Lives: A Cross Government Strategy for England.[http://webarchive.nationalarchives.gov. uk/20100407220245/http://www.dh.gov.uk/prod_consum_dh/groups/ dh_digitalassets/documents/digitalasset/dh_084024.pdf], accessed 5th April 2011.

11. Craig P, Dieppe P, Macintyre S, Michie S, Nazareth I, Petticrew M: Developing and evaluating complex interventions: the new Medical Research Council guidance. BMJ 2008, 337:a1655.

12. Kipping RR, Jago R, Lawlor DA: Obesity in children. Part 2: Prevention and management. BMJ 2008, 337:a1848.

13. Summerbell CD, Waters E, Edmunds LD, Kelly S, Brown T, Campbell KJ: Interventions for preventing obesity in children. Cochrane Database of Systematic Reviews 2005.

14. Lakshman R, Ogilvie D, Ong KK: Mothers' experiences of bottle-feeding: a systematic review of qualitative and quantitative studies. Arch Dis Child 2009, 94:596-601.

15. Wardle J, Guthrie CA, Sanderson S, Rapoport L: Development of the children's eating behaviour questionnaire. Journal of Child Psychology and Psychiatry 2001, 42:963-970.

16. Birch LL, Fisher JO, Grimm-Thomas K, Markey CN, Sawyer R, Johnson SL: Confirmatory factor analysis of the child feeding questionnaire: a measure of parental attitudes, beliefs and practices about child feeding and obesity proneness. Appetite 2001, 36:201-210.

17. Baughcum AE, Powers SW, Johnson SB, Chamberlin LA, Deeks CM, Jain A, Wjitaker RC: Maternal feeding practices and beliefs and their relationships to overweight in early childhood. Journal of Developmental and Behavioral Pediatrics 2001, 22:391-408.

18. Dennis $C L$ : The breastfeeding self-efficacy scale: Psychometric assessment of the short form. Jognn-Journal of Obstetric Gynecologic and Neonatal Nursing 2003, 32:734-744.

19. Dennis $C L$, Faux S: Development and psychometric testing of the breastfeeding self-efficacy scale. Research in Nursing \& Health 1999, 22:399-409.

20. Otsuka K, Dennis CL, Tatsuoka H, Jimba M: The relationship between breastfeeding self-efficacy and perceived insufficient milk among Japanese mothers. Jognn-Journal of Obstetric Gynecologic and Neonatal Nursing 2008, 37:546-555.

21. Gregory A, Penrose K, Morrison C, Dennis CL, MacArthur C: Psychometric properties of the Breastfeeding Self-Efficacy ScaleShort Form in an ethnically diverse UK sample. Public Health Nursing 2008, 25:278-284.

22. Ong KK, Langkamp M, Ranke MB, Whitehead $K$, Hughes IA, Acerini $C L$, Dunger DB: Insulin-like growth factor I concentrations in infancy predict differential gains in body length and adiposity: the Cambridge Baby Growth Study. Am J Clin Nutr 2009, 90:156-161.

23. Prasopkittikun T, Tilokskulchai F, Sinsuksai N, Sitthimongkol Y: Self-Efficacy in Infant Care Scale: development and psychometric testing. Nurs Health Sci 2006, 8:44-50.

24. Secco L: The infant care questionnaire: assessment of reliability and validity in a sample of healthy mothers. J Nursing Measurement 2002, 10:97-110.

25. Bandura A: Self-efficacy: The Exercise of Control. New York: Freeman; 1997.

26. Johnson F, Cooke L, Croker H, Wardle J: Changing perceptions of weight in Great Britain: comparison of two population surveys. BMJ 2008, 337: a494.

27. $\mathrm{FAO}, \mathrm{WHO}, \mathrm{UNU}$ : Human Energy Requirements. Food and Nutrition Technical Report Series 1. 2004.

28. Baranowski T, Perry C, Parcel G: How individuals, environments, and health behaviour interact; Social Cognitive Theory. In Health Behaviour and Health Education-Theory, Research and Practice. Edited by: Glanz K. USA: J Wiley; 2002:.

29. Luszczynska A, Schwarzer R: Social Cognitive Theory: Chapter 4. In Predicting Health Behaviours. Edited by: Conner M, Norman P. Maidenhead: Open University Press; 2005:

30. Ajzen I: The Theroy of Planned Behaviour. Organisational Behaviour and Human Decision Processes. 1991, 179-211.

31. McMinn A, van Sluijs E, Harvey N, Cooper C, Inskip H, Godfrey K, Griffin S: Validation of a maternal questionnaire on correlates of physical activity in preschool children. International Journal of Behavioral Nutrition and Physical Activity 2009, 6:81. 
32. Hume C, Ball K, Salmon J: Development and reliability of a self-report questionnaire to examine children's perceptions of the physical activity environment at home and in the neighbourhood. Int I Behav Nutr Phys Act 2006, 3:16.

33. Portney L, Waktins M: Foundations of Clinical Research: Applications to Practice. Upper Saddle River, New Jersey: Prentice-Halli, 22000.

34. Landis JR, Koch GG: The Measurement of Observer Agreement for Categorical Data. Biometrics 1977, 33:159-174.

35. Stevens J, Cornell CE, Story M, French SA, Levin S, Becenti A, Gittelsohn J, Going SB: Development of a questionnaire to assess knowledge, attitudes and behaviors in American Indian children. Am J Clin Nutr 1999, 69:773S-781S.

36. Lamping DL, Schroter S, Marquis P, Marrel A, Duprat-Lomon I, Sagnier PP: The community-acquired pneumonia symptom questionnaire - A new, patient-based outcome measure to evaluate symptoms in patients with community-acquired pneumonia. Chest 2002, 122:920-929.

37. Bolling K: Infant Feeding Survey 2005. The Information Centre 2007.

doi:10.1186/1479-5868-8-35

Cite this article as: Lakshman et al:: Development of a questionnaire to assess maternal attitudes towards infant growth and milk feeding practices. International Journal of Behavioral Nutrition and Physical Activity $20118: 35$

\section{Submit your next manuscript to BioMed Central} and take full advantage of:

- Convenient online submission

- Thorough peer review

- No space constraints or color figure charges

- Immediate publication on acceptance

- Inclusion in PubMed, CAS, Scopus and Google Scholar

- Research which is freely available for redistribution

Submit your manuscript at www.biomedcentral.com/submit 